\title{
Development and Psychometric Assessment of Risk Factors of Compassion Fatigue Inventory in Nurses
}

\author{
Mahdieh Sabery, PhD \\ Student Research Committee, School of Nursing and Midwifery, Shahid Beheshti \\ University of Medical Sciences, Tehran, Iran \\ Department of Medical Surgical Nursing, Faculty of Nursing and Midwifery, Kashan \\ University of Medical Sciences, Kashan, Iran
}

Mansoureh Zagheri Tafreshi, PhD

Nursing Management Department, School of Nursing and Midwifery, Shahid Beheshti University of Medical Sciences, Tehran, Iran

\section{Meimanat Hosseini, PhD}

Community Health Nursing, School of Nursing and Midwifery, Shahid Beheshti University of Medical Sciences, Tehran, Iran

\section{Jamileh Mohtashami, PhD}

Pyshiatric Nursing, School of Nursing and Midwifery, Shahid Beheshti University of Medical Sciences, Tehran, Iran

\author{
Abbas Ebadi, PhD \\ Behavioral Sciences Research Center, Lifestyle Institute, Baqiyatallah University of \\ Medical Sciences, Tehran, Iran \\ Faculty of Nursing, Baqiyatallah University of Medical Sciences, Tehran, Iran
}

\begin{abstract}
Background and Purpose: Identifying the risk factors of compassion fatigue is the basic step in designing effective interventions to prevent and manage compassion fatigue. This study developed an inventory of compassion fatigue risk factors and investigated its psychometric properties. Methods: This methodological study consisted of two phases: item pool generation through semistructured interviews with 13 nurses and reviewing of 38 related articles and the psychometric validation. Results: The initial item pool contained 62 items. The psychometric properties was examined and exploratory factor analysis revealed a four-factor structure. Risk Factors of Compassion Fatigue Inventory (RFCFI) contained 20 items. The Cronbach's alpha, intra-class correlation coefficient (ICC), and standard error of measurement (SEM) were $.86,0.83$, and 5.73 respectively. Conclusion: RFCFI is a short, self-reporting, valid, and reliable inventory for determining the risk factors of compassion fatigue in nurses and can be easily used by managers, nurses, and scholars.
\end{abstract}


Keywords: compassion fatigue; secondary traumatic stress; professional burnout; risk factor; validation studies; nursing

$\mathrm{E}$ mployment in healthcare professions, specifically nursing, exposes nurses continually to professional and emotional stressors due to long-term caring for and interaction with end-stage patients in pain, suffering, and distress leading to possible behavioral, emotional, and cognitive consequences in nurses (Showalter, 2010; Yoder, 2010). Joinson (1992) identified this phenomenon as the unique form of fatigue and called it compassion fatigue. The incidence of compassion fatigue has been reported in various wards of hospitals with varying rates (Sinclair, Raffin-Bouchal, Venturato, MijovicKondejewski, \& Smith-Macdonald, 2017), so that 21.6\% of oncology nurses (Cho \& Jung, 2014), 27.3\% of trauma nurses (Hinderer et al., 2014), 30\% of neonatal nurses (Sacco, Ciurzynski, Harvey, \& Ingersoll, 2015), 39.9\% of emergency nurses (Ariapooran, 2013), and $40 \%$ of ICU nurses (Elkonin \& Van Der Vyver, 2011) are at high risk of compassion fatigue. This phenomenon is associated with a wide range of destructive complications including extreme physical and mental exhaustion, depression, seclusion from family and society, loss of interest in previously enjoyable affaires, continuous mental involvement with others' problems, headaches, gastrointestinal problems, muscular rigidity, sleep disorders and insomnia, and self-ignorance affecting nurses' individual and professional interactions and their care-giving capabilities. It may also lead to increased turnover, absenteeism, work leave, sick leave, work days loss, safety risks, weak judgments, and finally decreased productivity in the organization (Berger, Polivka, Smoot, \& Owens, 2015; Branch \& Klinkenberg, 2015; Kelly, Runge, \& Spencer, 2015; Potter et al., 2010; Showalter, 2010). Despite the destructive factors of compassion fatigue in nurses, this phenomenon is preventable and treatable. Yet, many nurses and even nursing managers are not aware of it and its risk factors (Young, Derr, Cicchillo, \& Bressler, 2011). So, identification of risk factors of compassion fatigue is a basic step in prevention and management. An increased awareness of the risk factors of this phenomenon may help nurses learn the self-care strategies and effective coping skills to avoid the incidence of its destructive psychological outcomes in their domain (Chung, 2015). If the risk factors of compassion fatigue are not identified and treated effectively, this will greatly affect nurses' personal and professional life causing them to lose their compassionate care-giving ability forever (Bourassa, 2009; Mcholm, 2006; Potter et al., 2010). Seeing the absence of an instrument for identifying the risk factors of compassion fatigue in nurses, this study aimed at developing an inventory of such risks in nurses and validating it on the basis of the Iranian sociocultural context.

\section{BACKGROUND AND CONCEPTUAL FRAMEWORK}

A comprehensive search of reliable Persian and English databases yielded no specific tool for identifying and determining the risk factors of compassion fatigue in nurses in Iran and round the globe. However, several scales have been used over the last two decades to measure CF rate including Compassion Fatigue Self-tests, Secondary Traumatic Stress Scale, Scale of Compassion Fatigue, and Professional Quality of Life Scale (ProQOL). 
Despite the presence of such scales, some scholars still believe that the measurement of CF is challenging due to ambiguities in the conceptual model and its relation to other occupational stresses (Sinclair et al., 2017). It should be pointed out that none of the available instruments are based on nurses' experiences, and their efficacy has not been proved for use in nurses (Berger \& Gelkopf, 2011). Given that these instruments just measure the incidence of $\mathrm{CF}$ and the relevant concepts, thus not satisfying the goals of this study, the development, and validation of a reliable tool for identifying the risk factors of $\mathrm{CF}$ in nurses is mandatory. The controversies related to similarities and differences between CF and similar phenomena like secondary vicarious traumatization, traumatic stress, and burnout (Coetzee \& Klopper, 2010) have led to ambiguity and lack of recognition of the nature of compassion and its risk factors (Osofsky, Putnam, \& Lederman, 2008). On the other hand, very few studies have specifically dealt with $\mathrm{CF}$ risk factors in nurses containing contradictory assertions on the cause-effect relations between various risk factors and CF. For example, regarding the correlation between demographic variables and CF, Hansker et al. (2015) believe that there is no difference between CF in men and women while Craigie et al. (2016) have introduced age and gender (female) as important factors in developing $\mathrm{CF}$. Among the various risk factors, repeated and long-term exposure to patients in pain, suffering, and distress was one of the factors which correlated with development of CF by many scholars (Branch \& Klinkenberg, 2015; Chung, 2015; Coetzee \& Klopper, 2010; Frank \& Adkinson, 2007; Van Mol, Kompanje, Bakker, \& Nijkamp, 2014). Other CF risk factors included: demographic variables such as age and gender (Craigie et al., 2016; Hunsaker, Chen, Maughan, \& Heaston, 2015), variables of work and care, that is, long exposure to patients in pain, suffering, distress, and anxiety (Craig \& Sprang, 2010; Hooper, Craig, Janvrin, Wetsel, \& Reimels, 2010; Li, Early, Mahrer, Klaristenfeld, \& Gold, 2014; Owen \& Wanzer, 2014), the fuzzy borders between nurses and patients (Beck, 2011; Branch \& Klinkenberg, 2015; Showalter, 2010), and personality features, that is, high empathy, devotion, and self-sacrifice (Craigie et al., 2016; Showalter, 2010). Gates and Gillespie (2008) divided CF risk factors into three classes: nurse factors, patient factors, and work place factors. Severn, Searchfield, and Huggard (2012) and Cocker and Joss (2016) identified occupational and organizational factors as important risk factors contributing to the development of CF. Regarding the risk factors mentioned above and also the controversies in some of these parameters, this study embarked on developing a specific tool for identifying CF risk factors in nurses in the sociocultural context of Iran. Sinclair et al. (2017) believe that the presence of such an instrument will help nurse managers to identify the nurses at risk, develop effective interventions, and train them in comparative strategies and effective self-care approaches to protect and maintain them. Seeing the effect of social, political, and cultural factors in the incidence of CF (Craigie et al., 2016), this study aimed at developing and validating a specialized instrument for identifying and determining the CF risk factors in nurses in the sociocultural context of Iran.

\section{Method}

The present methodological study, conducted during 2015-2016, was part of a large-scale multicenter project on the concept of $\mathrm{CF}$ and consisted of two phases: first, production of instrument items using semistructured interviews with 13 nurses and literature review, and second, investigation of psychometric properties of the tool (Figure 1). 


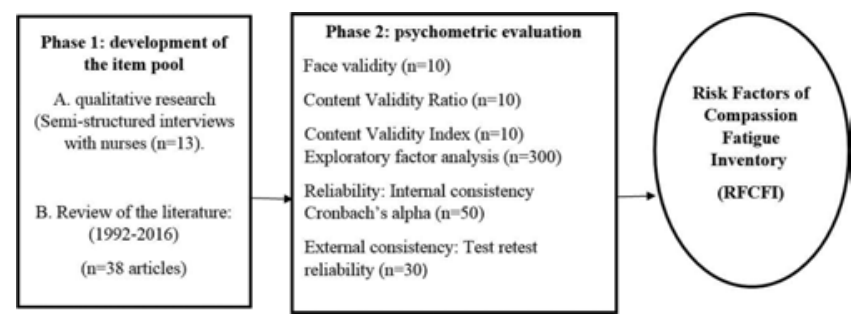

Figure 1. Procedures for instrument development.

\section{PROCEDURES FOR INSTRUMENT DEVELOPMENT}

\section{Phase 1: Development of the Items Pool}

To identify the risk factors contributing to the incidence of $\mathrm{CF}$, two methods were applied: data collection using interviews and literature review, and the combination of the data from both sections which resulted in the extraction of items pool.

Qualitative Section (Semistructured Interviews With Nurses). To identify the CF risk factors in the sociocultural context of the Iranian nurses, a qualitative approach was used to contemplate on the nurses' experiences and perception of these factors. To do so, semistructured interviews were performed with 13 nurses (10 nurses and 3 nurse managers) after obtaining informed written consent and elucidating the goals of the study. Purposive sampling was used with maximal diversity in age, gender, work experience, and work location to include a wide range of attitudes on CF risk factors presented by the key informants (Speziale, Streubert, \& Carpenter, 2011). The main interview questions were (a) As a nurse, have you ever got tired of patient care mentally or physically? (b) Which factors have caused mental or physical fatigue in you? (c) Under what conditions your fatigue increases? The interview then continued with some probing questions. The interview time varied between 30 and 45 minutes. Data collection reached saturation at 13th interview which yielded no new category in simultaneous analysis. The interview data were analyzed with qualitative content analysis using Graneheim and Lundman (2004) method. Regarding the qualitative approach, data collection and data analysis were done simultaneously. In so doing, each interview was listened to several times and then transcribed verbatim. Then, the transcripts were read several times to arrive at a general understanding of the main content. Then, condensed meaning units and primary codes were distilled and the codes were classified as subcategories on the basis of similarities and differences. Finally, the major categories were formed. Examples of meaning units, condensed meaning units, and codes are displayed in Figure 2.

\begin{tabular}{|c|c|c|}
\hline Meaning Unit & $\begin{array}{c}\text { Condensed } \\
\text { Meaning Unit }\end{array}$ & Code \\
\hline $\begin{array}{l}\text { "Our wards are extremely stressful. You have the } \\
\text { ward stress; you have the stress of ill neonates, } \\
\text { and you have the stress of equipment shortage. } \\
\text { (A nurse with 7-year work experience in NICU) }\end{array}$ & $\begin{array}{l}\text { Ward Stressful } \\
\text { Situations }\end{array}$ & $\begin{array}{l}\text { Multiple } \\
\text { Stressors }\end{array}$ \\
\hline
\end{tabular}

Figure 2. Examples of meaning units, condensed units, and codes in qualitative phase. 
Review of the Literature. In this phase, literature related to CF risk factors was searched in various databases including Medline, PubMed, and Science Direct using key words such as compassion risk, vicarious traumatization, burnout, secondary traumatic stress, and nurses' professional fatigue. In addition to English databases, a manual search was done in journals that had published articles related to CF. Seeing that CF has been noticed since two decades ago, all English studies related to $\mathrm{CF}$ and its risk factors entered the study without considering any time interval till 2016 using the mentioned key words in the titles, abstracts, or main texts. Inaccessibility of main body text was considered as the exclusion criterion. In literature review, a few instruments were found for measuring CF and the related concepts. Yet, no instrument was found for measuring CF risk factors in nurses. After omission of the repetitious cases, 1,971 articles were found in the initial search which were imported to EndNote. After studying the paper titles, 635 cases remained. Next, after reviewing the abstracts, 38 articles with more relevance to the topic of our study were selected. The selected studies were pondered on using qualitative content analysis (Graneheim \& Lundman, 2004). Subsequently, the codes related to CF risk factors were derived. Exemplars of meaning units, condensed meaning units, and codes obtained in this stage are presented in Figure 3.

To arrive at items pool, first the main categories and subcategories obtained from both qualitative sections of interview and literature review were compared and integrated, and an operational definition was provided for each. Next, several relevant items were written for each subcategory. The recommended items were revised by expert's panel and the items that conveyed the meaning of the subcategory more fully were selected.

\section{Trustworthiness}

To establish data rigor and stability, the participants were selected with maximal diversity in age, gender, and work experience. Also, the researchers tried to choose the most suitable meaning units after performing member checks, peer checks, and expert's opinions. The research team further tried to provide the follow up course of the research and characteristics of the population under study for others through vivid, accurate, and purposeful description of the research process (Elo \& Kyngäs, 2008).

\section{Phase 2: Psychometric Evaluation}

In this phase, to assess the psychometric properties of Risk Factors of Compassion Fatigue Inventory (RFCFI), various methods of validation such as face, content, and construct validity (exploratory factor analysis [EFA]) were used and Cronbach's alpha and intra-class correlation coefficient (ICC) were applied in the reliability phase.

\begin{tabular}{|l|c|c|}
\hline \multicolumn{1}{|c|}{ Meaning unit } & $\begin{array}{c}\text { Condensed meaning } \\
\text { unit }\end{array}$ & Code \\
\hline $\begin{array}{l}\text { "Empathic feelings may be a risk factor } \\
\text { for compassion fatigue"(Duarte, et al } \\
\text { 2016). }\end{array}$ & $\begin{array}{c}\text { Empathic feelings as } \\
\text { risk factor }\end{array}$ & Empathy \\
\hline
\end{tabular}

Figure 3. Examples of meaning units, condensed units, and codes in review of literature phase. 


\section{Face Validity}

Face validity is a subjective judgment performed by users to determine whether the instrument items are suitable for measuring the intended construct (Hardesty \& Bearden, 2004). It consists of both the qualitative and quantitative methods. To establish the qualitative face validity, 10 nurses were interviewed and their viewpoints were obtained on item difficulty levels, their suitability, and the presence of ambiguity (the likelihood of misperceptions of phrases or insufficiency in word meanings). After exerting the nurses' suggested corrections in the qualitative face validity phase, the inventory was given to the same 10 nurses in the quantitative face validity phase to determine the importance of each phrase and delete the inappropriate phrases. Then, the impact scores was calculated. If the impact score was equal to or $>1.5$, the phrase was rendered as suitable for the subsequent analyses and maintained (Broder, Mcgrath, \& Cisneros, 2007). To estimate item effect, the following formula was used:

\section{Impact Score $=$ Frequency $(\%) \times$ Importance}

Content Validity. In qualitative surveying of content validity, 10 experts in nursing, instrument development, and psychology were asked to review the items for grammaticality, suitable location, and proper diction (Gungor \& Beji, 2012). Then, the items underwent the final revision for literary composition by a team of coresearchers and an experienced nurse. Regarding quantitative content validity, the same 10 experts were asked to express their opinions on the necessity of the items using content validity ratio (CVR) and relevance of the items to the intended concept using content validity index (CVI) and to score them. According to Lawshe's table (1975), Ayre and Scally (2014), and the 10 experts, a CVR value of 0.62 is acceptable. Hyrkäs, Appelqvist-Schmidlechner, and Oksa. (2003) render I-CVI (Item Level CVI) of $>0.79$ as suitable, CVI between 0.7 and 0.79 as in need of adjustment and revision, and $<0.7$ as in need of deletion. Next, Scale-CVI/Ave was calculated by adding up CVI of individual items and divided by their number. A value $>0.9$ is favorable (Polit \& Beck, 2010).

Reliability and Item Analysis Before Factor Analysis. In reliability phase, to study the internal consistency reliability of the items with Cronbach's alpha, the initial RFCFI was completed in the pilot study by 50 new nurse participants (Di Lorio, 2006). Terwee et al. (2007) recommend Cronbach's alpha of .7-.9. Quantitative item analysis was also done to assess internal consistency of the instrument (Oermann \& Gaberson, 2016). A correlation coefficient $>0.8$ between pairs of items indicating that one of each pair may be redundant (Jones et al., 2009).

Construct Validity. EFA was used to establish construct validity which is one of the most commonly used methods for this purpose (Waltz, Strickland, \& Lenz, 2010). KMO is used to investigate sample volume sufficiency with a KMO index between 0 and 1 set as suitable for factor analysis. Bartlett's test of sphericity was used to determine the fit of factor analysis model. Principal components analysis (PCA) was used to extract the factors in factor analysis. Cumulative percentage of variance (CPV), law of Eigen value $>1$, and scree plot were used to facilitate the extraction of factors. No specific value is determined for CPV, yet, the minimal values of $\% 90$ and $50 \%-\% 60$ have been recommended for natural sciences and humanities, respectively. Orthogonal varimax rotation which is the most commonly used rotation technique, was used to create uncorrelated factors (Williams, Onsman, $\&$ Brown, 2010). The cut-off point of 0.4 was considered for factor loading. Williams et al. (2010) considered a sample volume of 300 as suitable for EFA. For this reason and 
also considering incomplete or unreturned questioners (subject attrition), 360 nurses were selected using convenience sampling method. Nurses employed at hospitals affiliated to Shahid Beheshti University of Medical Sciences in Tehran and Kashan and asked to complete the questionnaire. The inclusion criteria were "holding at least a BS degree in nursing, a work experience of at least 1 year, and inclination for participation in the study."

Reliability After Factor Analysis. To ensure of the reliability of the designed instrument, internal consistency reliability and Cronbach's alpha coefficient were determined after factor analysis and completing of 50 questionnaires by 50 new nurses aside from the previous sample. Next, to study the external consistency, RFCFI was completed twice at 2 -week intervals by 30 new nurses and the correlation between test scores and retest was estimated using ICC. Terwee et al. (2007) recommend intra-cluster correlation coefficient of at least 0.7. Furthermore, standard error of measurement (SEM) was estimated which is directly related to test reliability indicating whether the difference in various measurements is real or is due to measurement error (Terwee et al., 2007). A greater SEM indicates the lower reliability and accuracy of the tool and is suitable for comparing several tools (Atkinson \& Nevill, 1998).

\section{Statistical Data Analysis}

The gleaned data were analyzed with SPSS16 using descriptive statistics, EFA, Cronbach's alpha coefficient, and correlation coefficients.

\section{Ethical Considerations}

The approval of Committee of Ethics in Medical Research at Shahid Beheshti University of Medical Sciences was given in 31.10.2015 under no. SBMU2.REC.1394.46. All ethical principles were observed, informed written consent was obtained from each participant, information confidentiality was met, and the participants could leave the study voluntarily at any stage. Also, small gifts were considered to appreciate participation cooperation.

\section{RESULTS}

\section{Results of Phase 1: Items Development}

The Qualitative Section of Semi-structured Interviews. In the phase of interview analysis, first 584 primary codes were distilled. The similar codes were grouped into subcategories and after integrating 18 subcategories, 5 major categories including: "context-based variables, suffering from patients, personality traits, inability to help patients, and organizational challenges" were derived. To prepare the items pool, first the categories and subcategories were operationally defined and several items were recommended for each subcategory. The recommended items were investigated in several sessions by the coresearchers team. After omission of repetitious items and their logical edition, 69 items were obtained. An instance of the method of items production in the qualitative stage of the study is displayed in Table 1.

Literature Review Section. In the studies analysis phase, first 470 primary codes were obtained and grouped into 15 subcategories on the basis of similarities. Then, the similar subcategories were merged and three main categories including "personality traits, organizational challenges, and suffering from patients' pain" were formed. Like the previous 
TABLE 1. An Example of the Method of Production of Phrases in the Qualitative Section of the Study

\begin{tabular}{ll}
\hline \multicolumn{1}{c}{ Category } & \multicolumn{1}{c}{ Subcategory } \\
\hline \multicolumn{1}{c}{ Organizational challenges } & Challenge of resources and facilities \\
\hline $\begin{array}{l}\text { Operational definition of organizational } \\
\text { challenges: CF in nurses results from } \\
\text { organizational challenges such as challenges } \\
\text { of resources and facilities, specific properties } \\
\text { of clinical setting like difficult and laborious }\end{array}$ & $\begin{array}{l}\text { Operational definition of resources } \\
\text { and facilities: CF in nurses may result } \\
\text { from exposure to challenges of } \\
\text { resources and facilities like inadequate } \\
\text { resources and manpower, nonstandard } \\
\text { spaces and facilities, due to feeling }\end{array}$ \\
$\begin{array}{l}\text { aside from care-giving, and excessive } \\
\text { emphasis on bureaucracy and repetitious }\end{array}$ & $\begin{array}{l}\text { guilty due to insufficient equipment, } \\
\text { and inability to provide favorable } \\
\text { conditions for the patients. }\end{array}$ \\
time-consuming works. & \\
Recommended Items: & \\
-The number of staff in the ward is not sufficient. \\
-The space and staff number in ward are not standard. \\
-In the case of insufficient equipment and facilities in the ward, I \\
mentally get upset.
\end{tabular}

TABLE 2. An Example of the Method of Production of Phrases in the Literature Review

\begin{tabular}{ll}
\hline \multicolumn{1}{c}{ Category } & \multicolumn{1}{c}{ Subcategory } \\
\hline \multicolumn{1}{c}{ Patients' suffering and pain } & \multicolumn{1}{c}{ Continual mental occupation } \\
\hline Operational definition of patient' suffering: & Operational definition of continual \\
CF in nurses results from continuous mental & mental occupation: CF in nurses \\
occupation and agony due to patient's & results from continual mental \\
suffering. & $\begin{array}{l}\text { involvement by patients' problems. } \\
\text { Even during recreational times, the } \\
\text { nurse's mind is occupied by patients. It } \\
\text { reflects the scene of some patients and } \\
\text { affects negatively the nurse's mind. }\end{array}$
\end{tabular}

\section{Recommended Items:}

-My mind is always occupied by patients.

-I remind the scenes of some patients' sufferings.

-When I am immersed in patients, this affects my spirit negatively.

phase, to produce the items pool, first the operational definitions of the categories and subcategories were provided and a number of recommended items were devoted to each subcategory. After revision of the recommended items and deletion of repetitious ones, a total of 47 items were distilled. An example of the method of production of phrases in the literature review is given in Table 2. 


\section{Development of Items Pool}

Ultimately, the items pool was integrated with the primary 116 items obtained from integration of the qualitative phase items (69 items) and literature review (47 items). During several sessions, the items pool was deeply delved into and 35 items were omitted due to semantic overlap and 19 due to being repetitious by general agreement. Eventually, a 62item instrument with 4 components (context-based variables, organizational challenges, agony from patient's suffering, and inability to help patients) was developed by combining the results of literature review and interview phases and entered the psychometric measurement stage.

\section{Results of Phase 2: Assessment of Psychometric Properties of the Instrument}

Face Validity. In the qualitative face validity phase, no phrases were omitted and only the wording of four items was modified. However, in the quantitative face validity measurement, 7 items were omitted due to impact score $<1.5$ and the number of the items reached 55. For instance, the item: "I feel specific compassion towards patients with special diseases", was omitted due to impact score equal to 1.2.

Content Validity. In the qualitative content validity phase, the opinions of 10 experts were applied to the items and then, the items were investigated by the coresearchers team and an editor and finalized. Next, they entered the quantitative content validity phase. In this phase, 31 items were omitted on the basis of Lawshe's table (1975) owing to CVR $<0.7$. In CVI estimation, 2 items with CVI $<0.7$ were omitted again. The CVI of the whole instrument was obtained as 0.9 using the mean approach and finally 22 items remained (Figure 4).

\section{Results of Reliability Before Construct Validity}

The Cronbach's alpha of .86 was obtained for the 22-item instrument $(n=50)$. In item analysis, no item was omitted. Subsequently, the 22-item RFCFI was prepared for construct validation (EFA) using a five-point Likert scale ranging from strongly disagree $=1$ to strongly agree $=5$. In construct validation with EFA, 44 out of 360 questionnaires distributed by the first researcher (MS) to nurses were incomplete and 16 questioners were not returned back. Hence, a total of 300 questionnaires (response rate $=83.3 \%, n=300$ ) entered this phase. The demographic information of the participating nurses is presented in Table 3. The KMO coefficient was 0.83 in EFA indicating sample volume sufficiency. The results of Bartlett's test of sphericity were also statistically significant (approximate Chi-square $=21.32640, d f=231, p<.000$ ). The results of factor analysis with varimax rotation showed Eigen value $>1$, and a scree plot (Figure 5) demonstrated a four-factor structure with $50.30 \%$ total variance for 20 items. Two items were omitted during factor analysis due to factor loading $<0.4$. The items were assigned to the factor to which they were correlated more vividly. In the interpretation and labeling phase, the "mental concern" label was assigned to the first factor by reviewing items in this factor including seven items with variance explanation of $15.96 \%$. Professional-organizational challenges with seven items, lack of support with three items, and personality traits (self-sacrifice and commitment) with three items were the labels considered for other factors on the basis of the content of the items. Variance percentages for the three mentioned factors were $12.73 \%$, $12.15 \%$, and $9.46 \%$, respectively. Eventually, the inventory was finalized with four factors and 20 items. The labels, items number, and variance percentages are displayed in Table 4. 


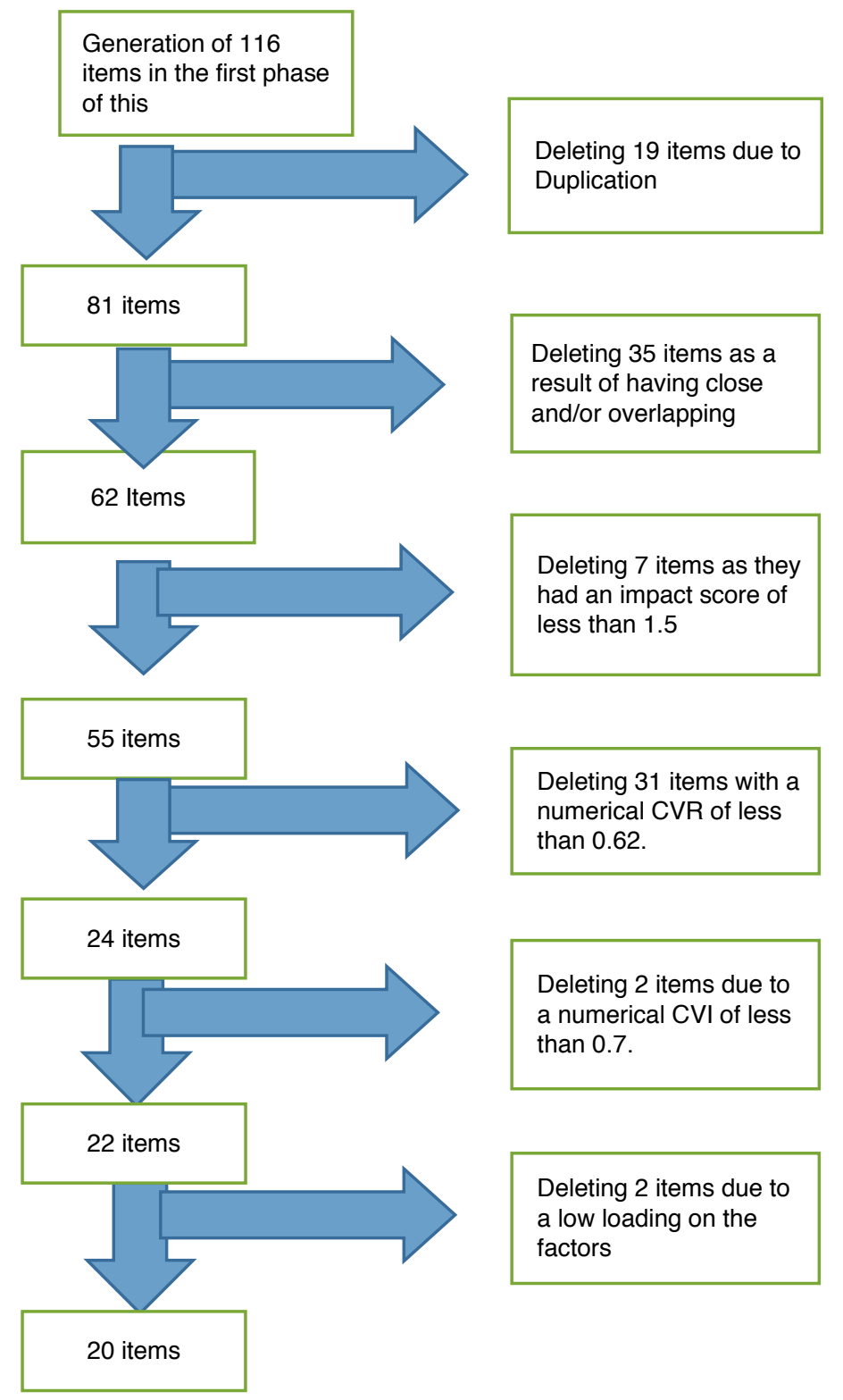

Figure 4. A summary of the instrument development and psychometric evaluation.

\section{Reliability}

Cronbach's alpha coefficnet was .85 after factor analysis for 20 items and four factors indicaitng appropriate internal consistency of the instrument. The ICC value among test scores and test loading was 0.81 . The reliability of the tool was also confirmed in the course of time. In the next stage, SEM of the inventory was 5.73 revealing the appropriate rigor and accuracy of the instrument. The values for Cronbach's alpha, ICC, SEM, mean, and standard deviation $(S D)$ of every factor and those of the whole inventory are exhibited in Table 4. 


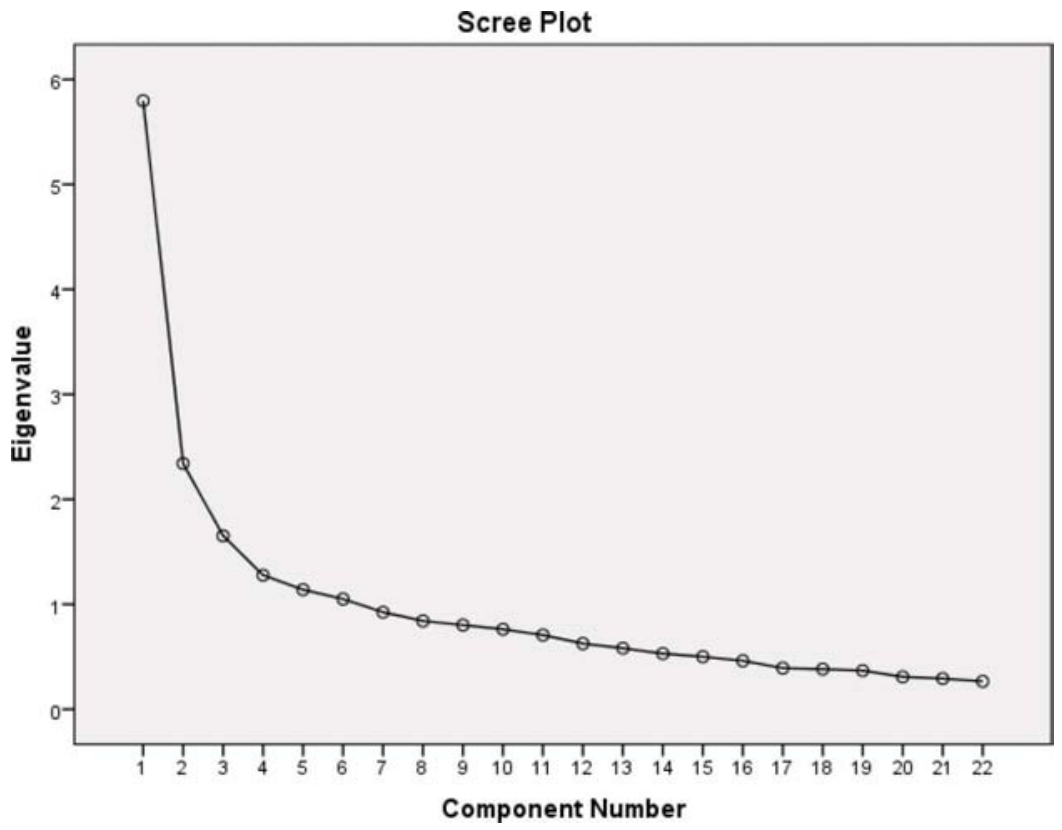

Figure 5. Scree plot for the sample in this study $(n=300)$.

TABLE 3. Demographic Information of the Participants

\begin{tabular}{llc}
\hline Variables & & Mean \pm SD or Frequency \\
\hline Age (Years) & & $21-54 \pm 6.86$ \\
Gender & Female & $244(81.33)$ \\
Marital status & Male & $56(16.67)$ \\
& Married & $101(33.67)$ \\
Employment status & Single & $199(66.33)$ \\
& Provisional official & $105(35 \%)$ \\
& Permanent official & $103(34.34 \%)$ \\
& Postgraduation mandatory & $47(15.66 \%)$ \\
Educational status & service & $45(15 \%)$ \\
\multirow{2}{*}{ Ward type } & Under contract & $277(92.34 \%)$ \\
& Bachelor's & $23(7.66 \%)$ \\
& Master's & $115(38.34 \%)$ \\
Total & Intensive care units & $101(33.66 \%)$ \\
\hline
\end{tabular}


TABLE 4. Factors, Items, and Factor Loadings for the RFCFI $(n=300)$

\begin{tabular}{|c|c|c|c|c|}
\hline Items & Factor 1 & Factor 2 & Factor 3 & Factor 4 \\
\hline $\begin{array}{l}\text { Sympathetic } \\
\text { interaction with the } \\
\text { patient, imposes } \\
\text { emotional burden on } \\
\text { me }\end{array}$ & .700 & & & \\
\hline $\begin{array}{l}\text { I internalize others' } \\
\text { problems and } \\
\text { damages }\end{array}$ & .696 & & & \\
\hline $\begin{array}{l}\text { My mind is always } \\
\text { engaged in patients }\end{array}$ & .655 & & & \\
\hline $\begin{array}{l}\text { I feel agony at } \\
\text { patients' pains and } \\
\text { sufferings }\end{array}$ & .649 & & & \\
\hline $\begin{array}{l}\text { I continually observe } \\
\text { the distress and } \\
\text { anxiety of the } \\
\text { patients' associates }\end{array}$ & .588 & & & \\
\hline $\begin{array}{l}\text { I continually face } \\
\text { disease, sorrow, and } \\
\text { sadness }\end{array}$ & .482 & & & \\
\hline $\begin{array}{l}\text { The workload in the } \\
\text { ward is heavy }\end{array}$ & & .696 & & \\
\hline $\begin{array}{l}\text { I have to work in } \\
\text { stressful situations }\end{array}$ & & .686 & & \\
\hline $\begin{array}{l}\text { Managers use more } \\
\text { punishment than } \\
\text { rewards }\end{array}$ & & .666 & & \\
\hline $\begin{array}{l}\text { People have too much } \\
\text { expectations from } \\
\text { nurses }\end{array}$ & & .560 & .488 & \\
\hline $\begin{array}{l}\text { Low evaluation of } \\
\text { nursing in society } \\
\text { affects my mood and } \\
\text { spirit at work }\end{array}$ & & .470 & & \\
\hline $\begin{array}{l}\text { I enjoy intimate close } \\
\text { relations with } \\
\text { workmates (nurses, } \\
\text { head nurses, and } \\
\text { physicians) }\end{array}$ & & .451 & & \\
\hline $\begin{array}{l}\text { Sympathetic and } \\
\text { repetitious responses } \\
\text { to patients' pain, } \\
\text { distress, and } \\
\text { sufferings makes me } \\
\text { mentally exhausted }\end{array}$ & & .417 & & \\
\hline
\end{tabular}


TABLE 4. Factors, Items, and Factor Loadings for the RFCFI $(n=300)($ Continued)

\begin{tabular}{|c|c|c|c|c|}
\hline Items & Factor 1 & Factor 2 & Factor 3 & Factor 4 \\
\hline $\begin{array}{l}\text { Lack of cooperation } \\
\text { on the part of my } \\
\text { colleagues spoils my } \\
\text { mood and spirit }\end{array}$ & & & .796 & \\
\hline $\begin{array}{l}\text { Lack of support by } \\
\text { superiors destroys my } \\
\text { spirit }\end{array}$ & & & .749 & \\
\hline $\begin{array}{l}\text { Physicians' disrespect } \\
\text { for nurses annoys me }\end{array}$ & & & .706 & \\
\hline $\begin{array}{l}\text { I feel committed to } \\
\text { serve others }\end{array}$ & & & & .747 \\
\hline $\begin{array}{l}\text { I prioritize others' } \\
\text { needs over mine }\end{array}$ & & & & .740 \\
\hline $\begin{array}{l}\text { I show self-sacrificing } \\
\text { behaviors }\end{array}$ & & & & .677 \\
\hline Adjusted variance & & $12.73 \%$ & $12.15 \%$ & $9.46 \%$ \\
\hline Cumulative variance & & $28.69 \%$ & $40.84 \%$ & 50.3 \\
\hline $\begin{array}{l}\text { Cronbach's alpha } \\
(n=50)\end{array}$ & & 0.74 & 0.74 & 0.7 \\
\hline $\operatorname{ICC}(95 \% \mathrm{CI})(n=30)$ & & $.69(.6-.75)$ & $.71(.62-.77)$ & $.62(.44-.73)$ \\
\hline SEM & & 2.98 & 1.16 & 1.36 \\
\hline $\begin{array}{l}\text { Mean (Standard } \\
\text { deviation) }\end{array}$ & & $27.71(4.10)$ & $12.32(2.32)$ & $11.77(1.73)$ \\
\hline
\end{tabular}

Note. ICC $=$ intra-class correlation coefficient; RFCFI $=$ Risk Factors of Compassion Fatigue Inventory; SEM = standard error of measurement.

\section{Description, Administration, and Scoring of the Instrument}

RFCFI is an inventory that identifies the CF risk factors in nurses. It is a valid and reliable self-reporting tool which is readily applicable to the Iranian nursing community. It entails 20 items and four factors including mental concern (items 2, 6, 7, 8, 9, 10, and 11), professional-organizational challenges (items 12, 13, 19, 20, 22, 15, and 1), lack of support (items 14, 16, and 17), and personality traits (items 3, 4, and 5). RFCFI entails 19 positive items and 1 negative item. The respondents should mark the choices in a five-point Liker scale ranging from strongly disagree $=1$ to strongly agree $=5$. The items are given equal weights. The total score of the whole instrument is estimated by summing up the points of each item. A higher score indicates greater CF risk factors in nurses. A summary of the instrument development and psychometric evaluation was shown in Figure 4.

\section{Discussion}

The goal of this study was to develop and assess the properties of RFCFI in nurses. It has been developed for the first time in Iran and in the world to identify the CF risk factors in nurses. The items of the tool are derived from integration of the results of the qualitative 
phase of interview with nurses and literature review and is developed in the Iranian sociocultural context. The results of the reliability and validity phase of the instrument indicated that this inventory with four factors (domains) and 20 items relevant to the intended goals is a specialized and homogenized inventory in which all the items measure the same construct. Stamm ( 2010) introduced the two concepts of compassion satisfaction and compassion fatigue in proQOL model in which CF consists of "secondary traumatization stress (STS)" and "burnout." In comparing RFCFI and proQOL, it can be said that averagely STS factor of the said model corresponds to the first factor (mental concern), and professional burnout corresponds to the second factor (professional-organizational challenges). The risk factors of mental concern in RFCFI relate to the caring aspect and the nature of service provision in nursing. The risk factors of this domain include daily long-term exposure to and observation of painful suffering patients, sympathetic interaction with the patients, and continual mental engagement with patients' pain and suffering all leading nurses to unconsciously absorb, internalize, and even experience the patients' problems and hurts (Boyle, 2011; Lombardo \& Eyre, 2011; Mason et al., 2014; Yoder, 2010). The risk factors of the second domain (professional-organizational challenges) are related to the organization and the profession which can be divided into two subcategories: organizational challenges and professional challenges. The risk factors of organizational challenges include excessive workload, stressful work conditions, unreasonable expectations from the nurses, and the policy of more punishment than rewards by managers which are totally consistent with previous studies (Aycock \& Boyle, 2009; Boyle, 2015; Craigie et al., 2016; Lombardo \& Eyre, 2011, Sorenson, Bolick, Wright, \& Hamilton, 2016). Professional challenges consist of items devoted to the nursing profession and its related challenges, specifically in the sociocultural context of Iran confirmed by the previous studies conducted in Iran (Farsi, Dehghan-Nayeri, Negarandeh, \& Broomand, 2010; Nikbakht Nasrabadi, Emami, \& Parsa Yekta, 2003). Problems such as lack of support, low evaluation of the nursing profession by the organization and society, and priority of treatment over prevention induced by physician-oriented climate governing the healthcare system in Iran, have resulted in nurses' physical and mental fatigue from their own perspectives so that when restorative processes for regaining the lost power are not undertaken by the organization, $\mathrm{CF}$ will occur in nurses. The third domain of RFCFI labeled "lack of support" is very important in the incidence of CF. Hunsaker et al. (2015) and Hensel, Ruiz, Finney, and Dewa (2015) introduced "lack of work support" and "lack of social support" as risk factors to approve this finding. Moreover, Cocker and Joss (2016) determined manager's weak support as organizational risk factors which are effective in the incidence of CF (Cocker \& Joss, 2016). Branch and Klinkenberg (2015) asserted that the manager's lack of support along with other factors affects nurses' ability for providing safe and appropriate care. Additionally, the expansion of peer support to prevent CF has been confirmed (Bourassa, 2009). Personality traits as the fourth domain have been referred to as risk factors in previous studies so that Figley (1995) and most scholars believe that nurses with characteristics such as high sympathy, self-sacrificing behaviors, commitment, and strong inclination for help are more vulnerable to CF (Abendroth \& Flannery, 2006; Perry, Dalton, \& Edwards, 2010; Sung, Seo, \& Kim, 2012). The professional-organizational challenges as a great category of CF risk factors indicate that prevention of CF will not be plausible by the nurses alone, rather, the community and organization also play a role in the incidence of CF (Boyle, 2015; Drury, Craigie, Francis, Aoun, \& Hegney, 2014; Hunsaker et al., 2015; Owen \& 
Wanzer, 2014). In other words, organizations ought to provide a protective and supportive climate for nurses to enable them to provide compassionate care for patients continually without physical, emotional or cognitive damages. Also, in addition to provision of their compassion satisfaction and occupational satisfaction, nurses can promote patient satisfaction, and increase safety of patient quality care (Boyle, 2015; Drury et al., 2014; Hunsaker et al., 2015; Owen \& Wanzer, 2014).

\section{CONCLUSION}

RFCFI is a self-reporting inventory used to determine the risk factors of CF in nurses with four factors and 20 items. This inventory with acceptable validity and reliability is very brief yet comprehensive and can be easily used by nurses, nurse managers, and scholars. It is the first instrument developed for assessing CF risk factors in nurses based on the sociocultural context of the Iranian community. It can be used in the healthcare system of different countries provided it is locally validated.

\section{The Nursing Implications for Practice, Research in Nursing Practice}

RFCFI increases the nurses' awareness and perception of CF risk factors. Nurses can identify the CF risk factors in themselves by this tool and maintain their own compassion and growth via self-care measures. Nurse managers also can acquire a comprehensive assessment of CF risk factors in nurses by the use of this inventory and design managerial interventions such as more endeavor for eliminating organizational challenges, social acculturation toward the professional status of nursing profession, informing nurses of CF risk factors, coping skills and strategies, provision of sufficient time for nurses' power renewal, and training in adaptation strategies and self-care of nurses' well-being to protect them leading to promoted professional satisfaction, improved quality care, and finally, organizational optimization.

\section{In Nursing Research}

Scholars may use RFCFI to assess risk factors of CF in nurses. After identifying the risk factors of $\mathrm{CF}$, researchers may design some studies to identify effective intervention for prevention of $\mathrm{CF}$, outcomes reduction and stuff protection.

\section{REFERENCES}

Abendroth, M., \& Flannery, J. (2006). Predicting the risk of compassion fatigue: A study of hospice nurses. Journal of Hospice \& Palliative Nursing, 8, 346-356. doi:10.1097/00129191200611000-00007

Ariapooran, S. (2013). The prevalence of secondary traumatic stress among nurses in iran, malayer: The predicting role of mindfulness and social support. International Journal of Community Based Nursing and Midwifery, 1, 156-164.

Atkinson, G., \& Nevill, A. M. (1998). Statistical methods for assessing measurement error (reliability) in variables relevant to sports medicine. Sports Medicine, 26, 217-238. doi:10.2165/00007256-199826040-00002 
Aycock, N., \& Boyle, D. (2009). Interventions to manage compassion fatigue in oncology nursing. Clinical Journal of Oncology Nursing, 13, 183-191. doi:10.1188/09.CJON.183-191

Ayre, C., \& Scally, A. J. (2014). Critical values for lawshe's content validity ratio revisiting the original methods of calculation. Measurement and Evaluation in Counseling and Development, 47, 79-86. doi:10.1177/0748175613513808

Beck C.T. (2011). Secondary traumatic stress in nurses: a systematic review. Archives of psychiatric nursing; 25(1):1-10. doi:https://doi.org/10.1016/j.apnu.2010.05.005.

Berger, R., \& Gelkopf, M. (2011). An intervention for reducing secondary traumatization and improving professional self-efficacy in well baby clinic nurses following war and terror: A random control group trial. International Journal of Nursing Studies, 48, 601-610. doi:10.1016/j.ijnurstu.2010.09.007

Berger, J., Polivka, B., Smoot, E. A., \& Owens, H. (2015). Compassion fatigue in pediatric nurses. Journal of Pediatric Nursing, 30, e11-e17. doi:10.1016/j.pedn.2015.02.005

Bourassa, D. B. (2009). Compassion fatigue and the adult protective services social worker. Journal of Gerontological Social Work, 52, 215-229. doi:10.1080/01634370802609296

Boyle, D. A. (2011). Countering compassion fatigue: A requisite nursing agenda. Online Journal of Issues in Nursing, 16, 2.

Boyle, D. A. (2015). Compassion fatigue: The cost of caring. Nursing, 45, 48-51. doi:10.1097/01.NURSE.0000461857.48809.a1

Branch, C., \& Klinkenberg, D. (2015). Compassion fatigue among pediatric healthcare providers. MCN: The American Journal of Maternal/Child Nursing, 40, 160-166. doi:10.1097/NMC.0000000000000133

Broder, H. L., Mcgrath, C., \& Cisneros, G. J. (2007). Questionnaire development: Face validity and item impact testing of the child oral health impact profile. Community Dentistry and oral Epidemiology, 35, 8-19. doi:10.1111/j.1600-0528.2007.00401.x

Cho, H. J., \& Jung, M. S. (2014). Effect of empathy, resilience, self-care on compassion fatigue in oncology nurses. Journal of Korean Academy of Nursing Administration, 20, 373-382. doi:10.11111/jkana.2014.20.4.373

Chung, J. K. (2015). Compassion fatigue and burnout in nursing: Asystematic literature review. Dissertation of Master of Health Sciences Degree. University of Canterbury. https://canterbury.libguides.com/rights/theses.

Cocker, F., \& Joss, N. (2016). Compassion fatigue among healthcare, emergency and community service workers: A systematic review. International Journal of Environmental Research and Public Health, 13, 618. doi:10.3390/ijerph13060618

Coetzee, S. K., \& Klopper, H. C. (2010). Compassion fatigue within nursing practice: A concept analysis. Nursing \& Health Sciences, 12, 235-243. doi:10.1111/j.1442-2018.2010.00526.x

Craig, C. D., \& Sprang, G. (2010). Compassion satisfaction, compassion fatigue, and burnout in a national sample of trauma treatment therapists. Anxiety Stress Coping, 23, 319-339. doi:10.1080/10615800903085818

Craigie, M., Osseiran-Moisson, R., Hemsworth, D., Aoun, S., Francis, K., Brown, J., . . Rees, C. (2016). The influence of trait-negative affect and compassion satisfaction on compassion fatigue in Australian nurses. Psychological Trauma, 8, 88-97. doi:10.1037/tra0000050

Di Lorio, C. K. (2006). Measurement in health behavior: Methods for research and evaluation. John Wiley \& Sons; United States.

Drury, V., Craigie, M., Francis, K., Aoun, S., \& Hegney, D. G. (2014). Compassion satisfaction, compassion fatigue, anxiety, depression and stress in registered nurses in Australia: Phase 2 results. Journal of Nursing Management, 22, 519-531. doi:10.1111/jonm.12168 
Elkonin, D., \& Van Der Vyver, L. (2011). Positive and negative emotional responses to work-related trauma of intensive care nurses in private health care facilities. Health SA Gesondheid, 16(1), 1-8. doi:10.4102/hsag.v16i1.436

Elo, S., \& Kyngäs, H. (2008). The qualitative content analysis process. Journal of Advanced Nursing, 62, 107-115. doi:10.1111/j.1365-2648.2007.04569.x

Farsi, Z., Dehghan-Nayeri, N., Negarandeh, R., \& Broomand, S. (2010). Nursing profession in Iran: An overview of opportunities and challenges. Japan Journal of Nursing Science, 7, 9-18. doi:10.1111/j.1742-7924.2010.00137.x

Figley, C. R. (1995). Compassion fatigue: Toward a new understanding of the costs of caring. In B. H. Stamm (Ed.), Secondary traumatic stress: Self-care issues for clinicians, researchers, and educators (pp. 3-28). Baltimore, MD, US: The Sidran Press.

Frank, D. I., \& Adkinson, L. F. (2007). A developmental perspective on risk for compassion fatigue in middle-aged nurses caring for hurricane victims in florida. Holistic Nursing Practice, 21, 5562; quiz 63-62. doi:10.1097/01.HNP.0000262018.49550.5a

Gardner III EK. Differences in Perceptions of Compassion Fatigue, Compassion Satisfaction, and Burnout Among Nurse Faculty. 2015. Indiana University of Pennsylvania. Theses and Dissertations (All). 834. 1-30-2015. http://knowledge.library.iup.edu/etd/834.

Gates, D. M., \& Gillespie, G. L. (2008). Secondary traumatic stress in nurses who care for traumatized women. Journal of Obstetric, Gynecologic, \& Neonatal Nursing, 37, 243-249. doi:10.1111/j.1552-6909.2008.00228.x

Graneheim, U. H., \& Lundman, B. (2004). Qualitative content analysis in nursing research: Concepts, procedures and measures to achieve trustworthiness. Nurse Education Today, 24, 105112. doi:10.1016/j.nedt.2003.10.001

Gungor, I., \& Beji, N. K. (2012). Development and psychometric testing of the scales for measuring maternal satisfaction in normal and caesarean birth. Midwifery, 28, 348-357. doi:10.1016/j.midw.2011.03.009

Hardesty, D, M, \& Bearden, W.O. (2004). The use of expert judges in scale development: Implications for improving face validity of measures of unobservable constructs. Journal of Business Research, 57(2), 98-107. doi:https://doi.org/10.1016/S0148-2963(01)00295-8.

Hensel, J. M., Ruiz, C., Finney, C., \& Dewa, C. S. (2015). Meta-analysis of risk factors for secondary traumatic stress in therapeutic work with trauma victims. Journal of Traumatic Stress, 28, 8391. doi: $10.1002 /$ jts. 21998

Hinderer, K. A., Vonrueden, K. T., Friedmann, E., Mcquillan, K. A., Gilmore, R., Kramer, B., \& Murray, M. (2014). Burnout, compassion fatigue, compassion satisfaction, and secondary traumatic stress in trauma nurses. Journal of Trauma Nursing, 21, 160-169. doi:10.1097/JTN.0000000000000055

Hooper, C., Craig, J., Janvrin, D. R., Wetsel, M. A., \& Reimels, E. (2010). Compassion satisfaction, burnout, and compassion fatigue among emergency nurses compared with nurses in other selected inpatient specialties. Journal of Emergency Nursing, 36, 420-427. doi:10.1016/j.jen.2009.11.027

Hunsaker, S., Chen, H. C., Maughan, D., \& Heaston, S. (2015). Factors that influence the development of compassion fatigue, burnout, and compassion satisfaction in emergency department nurses. Journal of Nursing Scholarship, 47, 186-194. doi:10.1111/jnu.12122

Hyrkäs, K., Appelqvist-Schmidlechner, K., \& Oksa, L. (2003). Validating an instrument for clinical supervision using an expert panel. International Journal of Nursing Studies, 40, 619-625. doi:10.1016/S0020-7489(03)00036-1

Joinson, C. (1992). Coping with compassion fatigue. Nursing, 22(116), 118-119, 120. doi:10.1097/ 00152193-199205000-00032 
Jones, P., Harding, G., Berry, P., Wiklund, I., Chen, W., \& Leidy, N. K. (2009). Development and first validation of the COPD assessment test. European Respiratory Journal, 34, 648-654. doi:10.1183/09031936.00102509

Kelly, L., Runge, J., \& Spencer, C. (2015). Predictors of compassion fatigue and compassion satisfaction in acute care nurses. Journal of Nursing Scholarship, 47, 522-528. doi:10.1111/jnu.12162

Lawshe, C. H. (1975). A quantitative approach to content validity. Personnel Psychology, 28, 563575. doi:10.1111/j.1744-6570.1975.tb01393.x

Li, A., Early, S. F., Mahrer, N. E., Klaristenfeld, J. L., \& Gold, J. I. (2014). Group cohesion and organizational commitment: Protective factors for nurse residents' job satisfaction, compassion fatigue, compassion satisfaction, and burnout. Journal of Professional Nursing, 30, 89-99. doi:10.1016/j.profnurs.2013.04.004

Lombardo, B., \& Eyre, C. (2011). Compassion fatigue: A nurse's primer. Online Journal of Issues in Nursing, 16, 3 .

Mason, V. M., Leslie, G., Clark, K., Lyons, P., Walke, E., Butler, C., \& Griffin, M. (2014). Compassion fatigue, moral distress, and work engagement in surgical intensive care unit trauma nurses: A pilot study. Dimensions of Critical Care Nursing, 33, 215-225. doi:10.1097/DCC.0000000000000056

Mcholm, F. (2006). Rx for compassion fatigue. Journal of Christian Nursing, 23, 12-19; quiz 20-21. doi:10.1097/00005217-200611000-00003

Nikbakht Nasrabadi, A., Emami, A., \& Parsa Yekta, Z. (2003). Nursing experience in iran. International Journal of Nursing Practice, 9, 78-85. doi:10.1046/j.1322-7114.2003.00404.x

Oermann, M. H., \& Gaberson, K. B. (2016). Evaluation and testing in nursing education. New York, NY: Springer Publishing Company.

Osofsky, J. D., Putnam, F. W., \& Lederman, J. C. S. (2008). How to maintain emotional health when working with trauma. Juvenile and Family Court Journal, 59, 91-102. doi:10.1111/j.17556988.2008.00023.x

Owen, R. P., \& Wanzer, L. (2014). Compassion fatigue in military healthcare teams. Archives of Psychiatric Nursing, 28, 2-9. doi:10.1016/j.apnu.2013.09.007

Perry, B., Dalton, J. E., \& Edwards, M. (2010). Family caregivers' compassion fatigue in long-term facilities. Nursing Older People, 22, 26-31. doi:10.7748/nop2010.05.22.4.26.c7734

Polit, D., \& Beck, C. (2010). Essentials of nursing research: Appraising evidence for nursing practice. New York:Lippincott Williams \& Wilkins.

Potter, P., Deshields, T., Divanbeigi, J., Berger, J., Cipriano, D., Norris, L., \& Olsen, S. (2010). Compassion fatigue and burnout: Prevalence among oncology nurses. Clinical Journal of Oncology Nursing, 14, E56-E62. doi:10.1188/10.CJON.E56-E62

Sacco, T. L., Ciurzynski, S. M., Harvey, M. E., \& Ingersoll, G. L. (2015). Compassion satisfaction and compassion fatigue among critical care nurses. Critical Care Nurse, 35, 32-42. doi: $10.4037 / \mathrm{ccn} 2015392$

Severn, M. S., Searchfield, G. D., \& Huggard, P. (2012). Occupational stress amongst audiologists: Compassion satisfaction, compassion fatigue, and burnout. International Journal of Audiology, 51,3-9. doi:10.3109/14992027.2011.602366

Showalter, S. E. (2010). Compassion fatigue: What is it? Why does it matter? Recognizing the symptoms, acknowledging the impact, developing the tools to prevent compassion fatigue, and strengthen the professional already suffering from the effects. American Journal of Hospice and Palliative Care, 27, 239-242. doi:10.1177/1049909109354096

Sinclair, S., Raffin-Bouchal, S., Venturato, L., Mijovic-Kondejewski, J., \& Smith-Macdonald, L. (2017). Compassion fatigue: A meta-narrative review of the healthcare literature. International Journal of Nursing Studies. 69. 9-24 doi:10.1016/j.ijnurstu.2017.01.003. 
Sorenson, C., Bolick, B., Wright, K., \& Hamilton, R. (2016). Understanding compassion fatigue in healthcare providers: A review of current literature. Journal of Nursing Scholarship, 48, 456465. doi:10.1111/jnu.12229

Speziale, H. S., Streubert, H. J., \& Carpenter, D. R. (2011). Qualitative research in nursing: Advancing the humanistic imperative. Lippincott Williams \& Wilkins. United States.

Stamm, B. H. (2010). The concise ProQOL manual. Pocatello, ID: ProQOL.

Sung, K., Seo, Y., \& Kim, J. H. (2012). Relationships between compassion fatigue, burnout, and turnover intention in korean hospital nurses. Journal of Korean Academy of Nursing, 42, 1087 1094. doi:10.4040/jkan.2012.42.7.1087

Terwee, C. B., Bot, S. D., De Boer, M. R., Van Der Windt, D. A., Knol, D. L., Dekker, J., . . De Vet, H. C. (2007). Quality criteria were proposed for measurement properties of health status questionnaires. Journal of Clinical Epidemiology, 60, 34-42. doi:10.1016/j.jclinepi.2006.03.012

Van Mol, M., Kompanje, E., Bakker, J., \& Nijkamp, M. (2014). Compassion fatigue and burnout among healthcare professionals in the ICU. Critical Care, 18, P19. doi:10.1186/cc13209

Waltz, C. F., Strickland, O. L., \& Lenz, E. R. (2010). Measurement in nursing and health research. Springer Publishing Company. United States.

Williams, B., Onsman, A., \& Brown, T. (2010). Exploratory factor analysis: A five-step guide for novices. Australasian Journal of Paramedicine, 8.3: 1-13. doi:10.33151/ajp.8.3.93.

Yoder, E. A. (2010). Compassion fatigue in nurses. Applied Nursing Research, 23, 191-197. doi:10.1016/j.apnr.2008.09.003

Young, J. L., Derr, D. M., Cicchillo, V. J., \& Bressler, S. (2011). Compassion satisfaction, burnout, and secondary traumatic stress in heart and vascular nurses. Critical Care Nursing Quarterly, 34, 227-234. doi:10.1097/CNQ.0b013e31821c67d5

Disclosure. Mahdieh Sabery collected the data, carried out the analysis, and wrote the first draft of the manuscript. Zagheri Tafreshi and Hosseini and Ebadi supervised the study and contributed to the writing process. Mohtashmi contributed to the study design and revised the manuscript. Ebadi supervised the study design, statistical analysis, and interpretation of data. All authors read and approved the manuscript.

Acknowledgments. Our special thanks to the nurses who participated in the study during the process of scale evaluation. We would also like to state our thanks to the research deputy of Shahid Beheshti University of Medical Sciences for supporting the study. The article is taken from a nursing PhD dissertation, Shahid Beheshti University of Medical Sciences, Tehran-Iran (Grant No: SBMU2.REC.1394.46).

Correspondence regarding this manuscript should be directed to Meimanat Hosseini, $\mathrm{PhD}$, Community Health Nursing Department, School of Nursing and Midwifery, Shahid Beheshti University of Medical SciencesTehran, Iran. E-mail: m_hosseini@sbmu.ac.ir 